\title{
On the Research Value of "Food Landscape" Planning in the Process of New Urbanization
}

\author{
Zhao Jie ${ }^{1}$, Wang Ye ${ }^{1}$, Wan Xuan ${ }^{2}$ \\ ${ }^{1}$ Environmental Design Department, Collage of Art Design and Media, Sanda University, Shanghai, China \\ ${ }^{2}$ Visual Communication Department, Collage of Art Design and Media, Sanda University, Shanghai, China
}

\section{Email address:}

willianm.zhao@hotmail.com (Zhao Jie), 2994276678@qq.com (Wang Ye), 751939880@qq.com (Wan Xuan)

\section{To cite this article:}

Zhao Jie, Wang Ye, Wan Xuan. On the Research Value of "Food Landscape" Planning in the Process of New Urbanization. Science Discovery. Vol. 9, No. 5, 2021, pp. 234-238. doi: 10.11648/j.sd.20210905.16

Received: September 9, 2021; Accepted: October 5, 2021; Published: October 19, 2021

\begin{abstract}
With the steady and rapid progress of the new urbanization process, the integration of urban and rural development has also become one of the main tasks of territorial spatial planning. In optimizing urban space governance, the planning and protection of permanent basic farmland for food production is also urgently needed. Our country's grain planting area is huge, and grain production is of strategic significance related to the state's independence and the sustainable and stable development of society. This is clearly reflected in a series of important documents of the Party and the State. Many important social and economic development policies today directly lead to changes in the food landscape paradigm. The food landscape is closely related to the implementation of these economic, social, technological and other aspects of policies and is inseparable. However, it is still rare to consider grain farmland as a landscape for systematic research and planning. Through the definition and classification of food, its strategic significance and the proportion of land area requirements, and the value discussion in the international perspective, this paper preliminarily puts forward the research value and significance of food production as a special landscape planning in territorial spatial planning. Put forward the important reference value of "food landscape" for the formulation and implementation of major national policies in the future, the continuous and in-depth exploration of new urbanization, the promotion of sustainable and coordinated urban and rural development, and the change of people's living and production methods.
\end{abstract}

Keywords: Food, Territorial Spatial Planning, Landscape

\section{新型城镇化进程中“粮食景观”规划研究价值刍议}

赵杰 ${ }^{1}$, 王烨 ${ }^{1}$, 万轩 ${ }^{2}$

${ }^{1}$ 上海杉达学院艺术设计与传媒学院环境设计系, 上海, 中国

${ }^{2}$ 上海杉达学院艺术设计与传媒学院视觉传达系, 上海, 中国

邮箱

willianm.zhao@hotmail.com（赵杰），2994276678@qq.com（王烨），751939880@qq.com（万轩）

摘要：随着新型城镇化进程稳步快速的推进，城乡融合发展也成为国土空间规划的主要任务之一。在优化城市空间治 理中，用于粮食生产的永久基本农田的规划和保护工作也刻不容缓。我国粮食种植面积巨大,粮食生产具有关系到国家 独立自主、社会持续稳定发展的战略意义, 这在党和国家一系列重要文件中都有显著体现。今天许多重要的社会与经 济发展政策直接导致粮食景观范式的改变。粮食景观与这些经济、社会、科技等方面的政策实施息息相关，不可分割。 但将粮食耕地考虑作为景观进行系统研究与规划尚不多见。本文通过粮食的定义与分类、其战略意义和在国土面积中 的比重要求、在国际视野中的价值探讨等方面初步提出粮食生产作为一种在国土空间中特殊景观规划的研究价值与研 
究意义。提出“粮食景观”对于未来国家相关重大政策的制定与实施、新型城镇化的持续深入探索、城乡持续协调发展 的推进以及人们生活生产方式的改变等方面的重要参考价值。

关键词：粮食，国土空间规划，景观

\section{1. 引言}

十九大报告首次提出乡村振兴战略并纳入党章, 将它 列为决胜全面建成小康社会需要坚定实施的七大战略之 一。2021年，中央一号文件再次显示国家对农村发展的高 度重视。

党的十九届五中全会审议通过的《中共中央关于制定 国民经济和社会发展第十四个五年规划和二 $\mathrm{O}$ 三五年远 景目标的建议》, 对新发展阶段优先发展农业农村、全面 推进乡村振兴做出总体部署, 为做好当前和今后一个时期 “三农”工作指明了方向[1]。随后的《关于全面推进乡村振 兴加快农业农村现代化的意见》中指出要“统筹布局生态、 农业、城镇等功能空间, 科学划定各类空间管控边界, 严 格实行土地用途管制”, “落实最严格的耕地保护制度”[2]。 对县级国土空间规划、县域内城乡融合发展、乡村特色风 貌规划建设都提出了迫切的要求。

在一些发达地区，城市和乡村之间的地域界限逐渐模 糊, 城乡生活方式不断融合, 城市与乡村之间的关系会更 加密不可分, 城市规划与乡村规划将会成为一项统筹进行 的统一规划。2021年4月发改委印发的《2021年新型城镇 化和城乡融合发展重点任务》对此提出了基本的规划要求, 指出要完成省市县三级国土空间规划的编制任务, “统筹 划定生态保护红线、永久基本农田、城镇开发边界三条控 制线”, 并提出加快推进城乡融合发展的要求[3]。

由此可见, 粮食生产是我国农业生产中一个异常重要 的部分, 粮食的自给自足对于社会稳定与经济发展具有国 家层面的战略意义。粮食作物的耕种面积在所有农作物耕 种面积中占比极高, 相对于我国国土面积也具有举足轻重 的地位。单从其面积来说, 就应当予以足够的重视和深入 的研究, 而粮食生产与社会心理、城乡结构调整、社会结 构优化等关乎社会与经济发展方面也有巨大的联系与影 响。因此, 本文所要提出并进行讨论的主要内容——“粮 食景观”, 作为一类特殊的景观类型, 具有一定的研究价 值。这类可划分为景观的现象在乡村历史发展和目前新型 城镇化与城乡融合发展中都十分常见, 但又是容易被“忽 略”或者从另一个角度来看具有一定难度进行规划与开发 的景观类别。由于低位的经济价值与收益的影响, 其景观 价值的研究和挖掘一直没有得到很好地挖掘; 特别是新型 城镇化与城乡融合对于农业的改变、现代农耕模式对未来 粮食生产的巨大影响都势必会产生新的景观和新的评价 体系、欣赏角度与利用方式。

本文旨在通过简要分析粮食作物在几个方面体现出 的重要意义和价值, 提出粮食景观规划研究的必要性, 以 期获得在国土空间规划上更多、更深层次和更全面的交流 探讨。
粮食耕种面积和质量保障是关系到国家安全的重要 内容, 粮食景观的合理策划与规划则能够极大提升粮食作 物作为可观赏可游䡯对象的附加价值, 为当地创造新的经 济增长点和景观形式。同时, 由于粮食耕种模式与国家重 大政策之间的紧密联系, 粮食景观的研究也是对多项国家 重大政策实施效果的真实的检验，是未来相关新政策制定 的重要参考依据。通过恰当的策划与规划, 也可以使粮食 耕种对环境产生更加积极的影响, 更加合理地综合利用多 种自然与社会资源。

现代粮食景观将以新的思路和方式进行策划与规划, 充分结合逐步兴起的新型生活方式与交通方式, 为人们创 造出更加新颖的景观体验; 为现代粮食生产和耕地保护创 造更为有效和有利的条件; 为城乡持续协调发展, 城镇化 的不断深入, 新型城镇模式探索等带来新的研究切入点。

\section{2. 粮食的定义与分类}

区别于其他景观, 粮食作物有其独有的要素特征, 而 首先需要明确的就是粮食的定义或者粮食的分类。

\section{1. 中国对于粮食的定义与分类}

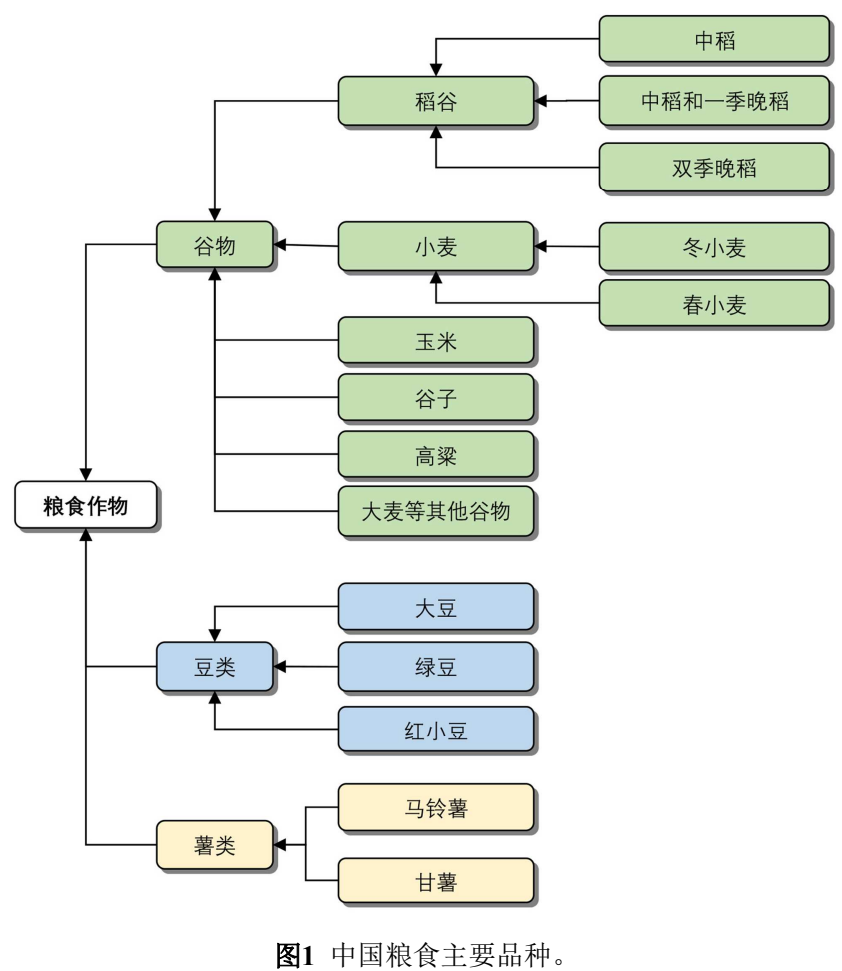

由国家发展和改革委员会起草并于2008年11月获得 国务院批准的《国家粮食安全中长期规划纲要 (2008-2020 年）》中, 确定了“粮食”一词的具体内容和对应的农业产 
品类型。粮食仅指谷物（包括小麦, 大米, 玉米等）、豆 类和块茎类作物 [4]。国家统计局在2013年出版了一系列标 题为“您身边的统计指标”的小手册, 其中的“粮食作物”一 册解释了与基本粮食生产有关的一些定义, 以及中国粮食 主要品种的统计数据和图表 (图1) [5]。

\section{2. 中国与国际组织在粮食定义与分类上的差异}

但“粮食”这一中文词汇在国际语境、特别是在英语这 一国际通用语言中通常以Food或Grain的形式出现。前者 可直译为“食物”, 后者可直译为“谷物”。Food一词与中文 “粮食”的区别在“联合国粮食及农业组织”（Food and Agriculture Organization of the United Nations）这一重要国 际农业机构的名称中就可以略见端倪。虽然此处中文翻译 将Food定义为“粮食”，但实际根据联合国粮食及农业组织 (以下简称为联合国粮农组织) 出版物《食物平衡表 (2001)》（FOOD BALANCE SHEETS）中的“食物成分 表” (FOOD COMPOSITION TABLES ) ${ }^{1}$, 其使用的“Food” 一词包括多达 16 类和 480 多个亚类内容 [6]; 在其公布的另 一份《粮农组织食品价格指数》（FAO Food Price Index） 统计中, 还考虑了五类食物价格指标, 涉及谷物、植物油、 牛奶、肉和糖的指标, 它们被视为国际语境中“粮食”的主 要成分。

因此, 与联合国粮农组织使用的Food一词最接近的中 文词语是“食物”。在之前提到的《国家粮食安全中长期规 划纲要 (2008-2020年) 》中也使用了这种更广泛的概念, 即除粮食本身外, 还包括其他种类的农作物和产品, 例如: 食用植物油、肉类、家禽、蛋、奶和水产品等。

不过在中国的各种统计和政策制定中，“粮食”一词通 常是主要目标用语, 而非“食物”。例如, “粮食安全”, 这 也是联合国粮农组织关注的一个主题, 即Food Security, 虽然其所表达的重点是基本食物, 而不是联合国粮农组织 特有的更广泛食物的概念, 但与中文中常用的“粮食”一词 在范畴上仍然更为宽泛一些。

粮食所对应的另一个常用英文词语是Grain, 通常在 中文中被称为“谷物”, 但由之前中国粮食类别和谷物类别 的图表中可以看出, 其分类方式与联合国粮农组织对谷物 的分类方式不同。在联合国粮农组织的《谷物月报》

(Monthly News Report on Grains) ${ }^{2}$ 中, 介绍了由国际谷 物理事会 (International Grains Council) 起草的《谷物市 场报告》（Grain Market Report），其中谷物分为四类: 小麦、玉米、大豆和水稻。在其《世界粮食形势谷物供求 摘要》 (FAO Cereal Supply and Demand Brief of World Food Situation） ${ }^{3}$ 统计中谷物类别分为四类: 小麦, 粗粮, 玉米和水稻。在所有这些分类中, 都没有豆类和块茎类的 分类, 后两者也是中国较为常见的基础食物种类。

如果说“谷物”一词在中英语境中类别较为接近, 那么 我们常用的“粮食”这个概念则比国际定义要狭窄许多。这 也是粮食作物在我国所具有的独特性。

1 http://www.fao.org/docrep/003/X9892E/X9892e05.htm\#P8217_125315.

http://www.fao.org/economic/est/publications/grains-publications/monthly-n ewsreport-on-grains-mnr/en/.

$3 \mathrm{http}: / /$ www.fao.org/worldfoodsituation/en/.

\section{3. 粮食的战略意义与国土比重的保障}

通过上文可以看出, 粮食的类别在所有农作物类别中 仅占较小一个部分, 但以耕种面积和产出计算则达到了惊 人的占比, 更重要的是其维护国家安全稳定的战略意义。

\section{1. 粮食生产的战略意义}

根据上述《国家粮食安全中长期规划纲要 (2008-2020 年）》要求, 我国粮食自给率应至少为 $95 \%$, 大米和小麦 应完全自给, 玉米也应充分自给自足。其他重要供给, 例 如畜牧业和渔业产品, 也应充分实现自给自足, 但不受数 量和组织方式的限制。因此可以说, 粮食作物 (谷物、豆 类和块茎类）的生产是保障国家安全和基本供给的关键。

这种独特的政策与中国政治文化和社会心理都有密 切的联系。历史上反复出现的可怕饥荒, 近现代中国被列 强不断的侵犯, 当代中国由于政体和社会发展模式的特殊 性而被一些国家排斥和孤立等等的过往与现实, 都时刻提 醒我们独立自主的重要性和必要性。基本生活资料的自给 自足是这种独立性的前提, 粮食生产则是最重要的保障。

\section{2. 粮食生产在国土面积比重上的保障}

中国人口基数大，农业生产方式相对发达国家还有所 差距, 且基于国际环境和历史经验考虑, 粮食耕地在量与 质的保护上仍处于极其重要的地位。中央政府颁布的 18 亿 亩红线、基本农田保护、永久基本农田保护等国家政策是 对粮食耕种重要性的回应, 这是其他任何国家都不曾有的。

18 亿亩这一个数字, 是由国土资源部于 2005 年进行的 土地利用调查后得出的结论。2008年，国务院通过了《全 国土地利用总体规划纲要（2006年至2020年）》，修订了 该目标, 确定了保留用于粮食耕种的土地面积到2010年应 达到18.18亿亩（1.212亿公顷）, 到2020年应达到18.05亿 亩（约1.203亿公顷）[7]。这一面积保障措施足以确保粮 食的自给率达到所要求的 $95 \%$ 。这一组数字使得粮食生产 所要求的可耕种土地面积约占到全国可耕种土地总量的 $80 \%[8]$ 。

除了维持相当于 18 亿亩耕地的红线外, 上述《全国土 地利用总体规划纲要》中还引入了进一步的约束目标, 即 所谓的基本农田面积, 其最低要求为 15.6 亿亩（1.04亿公 顷）。这些土地用于那些对基本粮食生产有直接或间接影 响的粮食作物。

为了严格遵守设定的红线目标, 该纲要为每个省、自 治区和直辖市规定了面积指标, 确定了要保留的耕地总面 积, 基本农田保护面积的百分比, 以及其他建筑用地指标 和标准等。特别是根据《土地管理法》规定, 基本农田保 护面积必须至少占红线政策所保护耕地面积的 $80 \%$ 。2020 年起施行的 《中华人民共和国土地管理法》第三次修正案 中以“永久基本农田”概念全面替代了第二次修正案中的 “基本农田”[9]。近期国家发展和改革委发布的《2021年新 型城镇化和城乡融合发展重点任务》再次强调了新型城镇 化和城乡融合发展中永久基本农田界限的划定与保护。

由此可见，中国的粮食作物无论是从其国际社会分类 方式的特殊性, 还是在国家战略中的重要性, 以及在国土 
面积中的比重等方面都是具有一定研究价值的景观现象, 如此大面积的特殊性质国土如果从景观角度进行适当与 合理的规划和开发利用, 将是推动社会与经济发展以及城 乡融合进程的又一助力。

\section{4. 粮食景观价值在国际化视野下的思考}

粮食作物生产与社会历史发展和国家政策演变息息 相关, 其景观层次的规划建设必然也将蕴含和映射这种与 社会和国家之间的关系。

\section{1. “景观”概念的诞生与原初含义}

“景观”一词在中文中实际是一个外来词 ${ }^{4}$, 经过两次转 义而来[10]。它成为一个社会性语言其实与这一词语的诞生 和演变具有紧密联系。这在欧洲语系中可以清晰地看到。 在欧洲, 景观一词相对于其使用的文化背景可以具有不同 的含义 [11]。从词源学方面来看, 景观一词在欧洲具有多种 语言表达: landschap (荷兰语), landaschaft(德语), landscape (英语), paysage (法语), paisaje (西班牙语) 和landscape (意大利语) ......这些术语的前叒“land”在不同语言中都具 有“开放场地”的概念。另一种前缀“pays”, 则具有“界定的 土地或区域”的含义, 类似于制度上界定的地区, 是由拉丁 文的“pagus”———个已确定的地点”, “一座村庄”一一衍 生而来的[12]。所有的后缀schap, schaft, scape, age, aje 等指的是“对现实的整体感知”、“相类似对象的组合”、“环 境的集体外观”等含义[13]。可以看出, 景观这个词语是对 开放场地或界定区域的一种整体感受与认知。

这些术语最初没有任何美学意义, 只是在16世纪上半 叶主要通过绘画和文学艺术才被赋予确切的美学认知, 从 而使人们看到这个词语时的第一反应就是美学上的感受。 实际上, 当“景观”一词在1462年首次以荷兰语出现时, 它 却是与保护填海所获得的领土免受海洋侵蚀的政策紧密 相关而被创造出来的。

“因此，这个术语本身就包含对未来的预测，而从这 个意义上说这是很有趣的事情: 这关乎一个领土计 划。......这个领土实际上是由政治体系和社会控制的空 间，......景观即是这个计划，是使得农业区域扩张以赡养 人口的领土远景”。“景观 .......并不是纯粹源于艺术，它是 一个政治和经济计划”[14]。

\section{2. “景观”的美学拓展}

景观一词在欧洲随着荷兰景观画作的风行而扩散开 来, 景观也逐渐从较为常见的宗教人物肖像或人物活动的 背景中脱离出来, 成为绘画的主角。

4 根据李树华在《景观十年、风景百年、风土千年一一景观、风景 与风土的关系探讨我国园林发展的大方向》的说法, 景观这个中文词语 的产生是1902年左右由日本植物学家三好学(Miyoshi Manabu)创造的, 该词源于德国释义语兰德沙夫特（Landschaft），用于表示日本的植物 学学科, 其原始含义是“植物园”。1930年, 陈植在《造园学概论》一书 的参考书目中通过三好学《日本植物景観》一书的书名首次将“景观”一 词展现给中国读者。
莱昂纳多·达·芬奇的“有河的风景”（1473年）（图2） 可以被视为西方艺术中的“第一幅纯粹的景观画作”，尽管 只是一幅草图, 但其内容已经不受神圣或玟渎的题材的影 响。艺术家以非凡的热情描绘了自然的每一个细节，揭示 了对自然的无限兴趣和一种非凡的表现纯真, 使景观成为 平衡与和谐的象征性代表。这种象征性的意愿对于后来的 伟大风景画家来说是相当普遍的。

艺术史上的另一幅名画《暴风雨》(乔尔乔内, 约 1505 年）（图3）中也没有展示明确的神圣参考对象, 而是将 风景作为绘画叙事的核心。这幅画的中心是一种令人眼花 缭乱且占主导地位的气象现象, 而人物则纯粹承担着对画 作内容描述的支撑作用。

这幅画为广大西方公众所熟知, 通过对一种政治宣言 在景观上的隐喻解读, 传达了帕多瓦城在结束卡拉拉宗主 保护关系之后同时遭受瘟疫和威尼斯骚扰的戏剧性情景。 景观成为这幅画的独特主题, 但不是作为一个自然主义的 实体, 而是作为一种概念抽象, 是在历史进程和当下令人 眼花缭乱的直觉之间、自然与人类行为之间的翻转。这幅 作品在艺术史上的价值也存在于这种多重含义中。

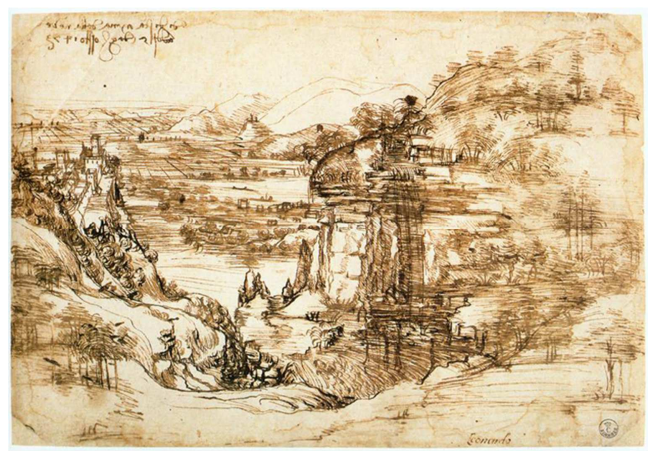

图2《有河的风景》莱昂纳多·达·芬奇 1473年。

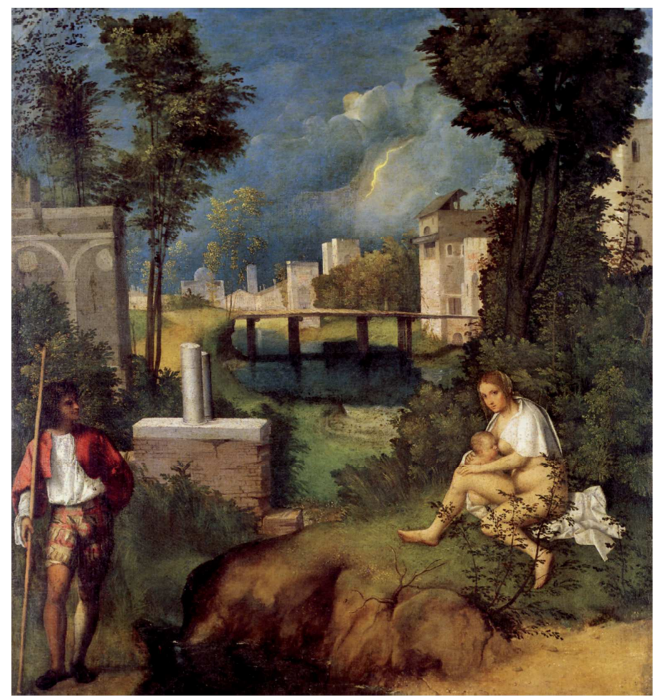

图3 《暴风雨》 乔尔乔内 约1505年。

\section{3. “景观”的美学拓展}

中国传统上与景观相对应的词语是“风景”，对风景的 欣赏和人为创造景观源自山水画创作上的独立[15]。中国山 
水画兴起也正处于魏晋南北朝社会剧烈动荡和变革的时期。 当时的知识分子开始重新审视社会, 从精神层次来考虑社 会, 将这种思索和反馈通过画作和对风景的营造表达出来。

因此, 可以说景观 (风景) 无论是作为一个名词还是 作为一种现象, 其产生是具有政治（政策）特征的, 或者 说是与政治（政策）具有密切联系的。从这一方面来看, 粮食景观与生俱来便带有景观原初的本质与含义。通过国 家战略和政策的大力宣传, 在全社会范围内广泛传播的记 忆和价值体系将赋予这种分布在全国的既常见又特殊的 现象以社会情感力量, 从而使其成为一种具有特别含义的 “景观”。

\section{5. 结论}

中国地域辽阔, 各地方自然条件差异较大, 因此粮食 种植方式和形成的相应景观形式也具有较大不同, 特别是 东部和西南地区。西南地区由于地形地貌限制, 仍以传统 种植方式为主, 粮食种植区域多呈现典型马赛克斑块形式, 村落与种植区域依附关系紧密。东北地区和东部平原及沿 海地区在大型机械化和新型农业合作化等条件的推动下, 形成新型的粮食耕种和生产模式, 粮食种植正逐步与村落 脱离, 传统的乡村概念和形式也正在此形势下发生巨大的 转变。一些集中化和产业化程度较高地区的粮食种植不再 是传统意义上乡村景观的一个组成部分, 正逐步形成一种 新的景观范式。

现代粮食景观将以新的思路和方式进行策划与规划, 充分结合逐步兴起的新型生活方式与交通方式, 为人们创 造出更加新颖的景观体验; 为现代粮食生产和耕地保护创 造更为有效和有利的条件; 为城乡持续协调融合发展, 城 镇化的不断深入, 新型城镇模式探索等带来新的研究切入 点。粮食种植将成为一种具有多种功能的农业生产方式。 粮食景观将成为一种新型的景观形式。

同时, 粮食种植区域的保护, 特别是基本农田的保护 是一项常抓不解的工作，也是一项十分重要、关系到国家 安全的工作。但这些政策有时没有得到广泛而深刻的了解 和认识。同时, 粮食种植区域“美”的特征, 粮食作为作物 之外的附加价值, 以及所表达的深层社会与经济意义等也 都没有通过其景观形态很好地表达出来。这些都是粮食景 观所具有的价值和意义。同时, 粮食景观的研究也是对多 项国家重大政策实施效果的真实的检验, 是未来相关新政 策制定的重要参考依据。

粮食耕种面积和质量保障是关系到国家安全的重要 内容, 粮食景观的合理策划与规划则能够极大提升粮食作 物作为可观赏可游憩对象的附加价值, 为当地创造新的经 济增长点和景观形式。同时, 由于粮食耕种模式与国家重 大政策之间的紧密联系, 粮食景观的研究也是对多项国家 重大政策实施效果的真实的检验，是未来相关新政策制定 的重要参考依据。通过恰当的策划与规划, 也可以使粮食 耕种对环境产生更加积极的影响, 更加合理地综合利用多 种自然与社会资源, 为新型城镇化生态空间建设创造更加 广阔的天地。

\section{致谢}

本文受上海杉达学院博士专项基金项目资助, 项目编 号: 2019BSZX04。

\section{参考文献}

[1] 中共中央关于制定国民经济和社会发展第十四个五年规划 和二 $\bigcirc$ 三五年远景目标的建议, 2020.10.29.

[2] 关于全面推进乡村振兴加快农业农村现代化的意见，中共 中央、国务院, 2021.1.4.

[3] 2021年新型城镇化和城乡融合发展重点任务, 发改规划 (2021〕493号,国家发改委,2021.4.8.

[4] 国家粮食安全中长期规划纲要 (2008-2020年), 国家发改委, 国发[2008]24号,2008.11.

[5] 您身边的统计指标,国家统计局,2013.10.

[6] 食物平衡表(2001)[FOOD BALANCE SHEETS],联合国粮 农组织,2001.

[7] 全国土地利用总体规划纲要（2006年-2020年）,国土资源 部,2008.10.6.

[8] 关于第二次全国土地调查主要数据成果的公报,国土资源 部，国家统计局，国务院第二次全国土地调查领导小组办 公室, 2013.12.31.

[9] 中华人民共和国土地管理法,全国人大常委会, 2019.8.26.

[10] 李树华.景观十年、风景百年、风土千年一从景观、风 景与风土的关系探讨我国园林发展的大方向[J]. 北京, 中国 园林,2004年12期:29-31.

[11] Valorani C.," Lecture 5. Paesaggio e nuovi paradigmi per il territorio" in BAIANI B., CRISTALLO V., SANTANGELO S., (a cura di), "Lectures \#3 design, pianificazione, tecnologia dell'architettura", Roma, Rdesignpress, 2014, pp. 105-128.

[12] Olivieri M., Il paesaggio: un quadro e alcune definizioni utili, in AA. VV., Lezioni di Dottorato 2005 - 2007. Temi e metodi di ricerca, Papers del DIPTU, n.2, Roma, Aracne Editrice, 2008.

[13] Jakob M., Paesaggio e letteratura. Firenze, Leo S. Olschki, 2005, pp.20-21.

[14] Luginbühl Y., Rappresentazioni sociali del paesaggio ed evoluzione della domanda sociale. in B. Castiglioni, M. De Marchi, Di chi è il paesaggio? Milano, FrancoAngeli Edizioni, 2009, pp.59-67.

[15] 杨锐.“风景”释义[J].北京,中国园林,2010年第9卷:1-3. 